\title{
Resenha
}

\section{Ampliando os horizontes do Direito da Saúde ${ }^{1}$}

\author{
Broadening the horizons of Health Law \\ La ampliación de los horizontes de la Ley de Salud
}

Lourdes Lemos Almeida ${ }^{2}$

O livro que ora se resenha, resulta da homenagem do conjunto de associados do Centro de Direito Biomédico ao Professor Doutor Guilherme de Oliveira, a fim de para além de render a justa homenagem, fazer uma cartografia do direito da saúde no vasto espaço da língua lusófona.

A coletânea congrega capítulos ricos em doutrina para o direito da saúde, a começar pela visão epistemológica da área do conhecimento, que acaba por encontrar uma vasta terminologia para a definição do tema em estudo.

Para isso, o texto da lavra de João Carlos Loureiro aborda as diferentes concepções, em língua portuguesa, do objeto de estudos: direito médico, direito biomédico, direito da (bio) medicina, direito sanitário, direito da saúde, biodireito, direito da bioética e direito da vida, e ainda considera o direito da farmácia, do medicamento, direito veterinário e direito da enfermagem.

Inicia sua dissertação citando o caso dos Países Baixos em que o direito da saúde firmou tradição desde os anos 50 referindo-se ao Gezondheidsrecht em um direito autônomo da saúde, bem como a tradição alemã marcada pelo Arztrecht, literalmente o direito médico.

A fórmula direito sanitário caiu em desuso em Portugal, mas revela alguma pujança no Brasil, e remete ao direito da política sanitária, tendo a higiene e política sanitária os objetos de estudo, sendo sinônimo de direito da saúde pública.

\footnotetext{
${ }^{1}$ Loureiro, J.; Pereira, AD; Barbosa, C. Direito da Saúde: estudos em homenagem ao Prof.Dr. Guilherme de Oliveira Coimbra: Almedina, 2016

${ }^{2}$ Mestre em Saúde Coletiva pela Universidade de Brasília. Gerente do Núcleo de Gestão e Planejamento do Conselho Nacional de Secretários de Saúde - Conass. Email: lourdes.almeida@conass.org.br
} 
O direito da medicina poderia ser apresentado como o conjunto de princípios e regras que disciplinam os cuidados da saúde. A par do direito penal e do direito civil, o impacto constitucional em geral e os direitos fundamentais em especial alargaram as áreas de juspublicização.

Já o direito da biomedicina foi cunhado em 2008, por Rüdiger Zuck³ designando a interpenetração entre a biologia e medicina e, em geral, das ciências da vida, que alteraram a própria prática médica, considerando dimensões holísticas. Trata-se de um território interdisciplinar que articula medicina e biologia, associa medicina humana com os métodos da biologia molecular e da biologia celular.

O direito da saúde, em referência ao pensamento jurídico do Século XIX, encontrase a definição de polícia sanitária, conformando-se no direito da saúde pública.

E mais ainda, o biodireito e o direito da bioética, além do direito dos cuidados da saúde, o direito da vida, o direito hospitalar, assumindo que a saúde é uma acepção lata.

O direito da saúde é um direito jovem, misto e autônomo, um direito de bens, posições jurídica e de relações.

No texto de autoria de Fernando Gomes, a deontologia e a bioética dialogam em uma construção dialética, assumindo que o termo bioética foi utilizado pela primeira vez pelo pastor protestante alemão Paul Max Fritz Jahr, em 1927, em um artigo que tratava do relacionamento ético entre homem, os animais e as plantas, ou seja, o relacionamento ético entre as formas de vida.

O capítulo "The research methodology in Health Law", de Delduque, MC e Alves, SM, discute sobre o alargamento da pesquisa em direito da saúde, para além da pesquisa jurisprudencial, doutrinária e jurídico-formais posto que está envolto com questões médica, biológicas, políticas, sociais, econômicas que importam a adoção de métodos científicos diversos para sua completa compreensão.

A coletânea ainda conta com texto sobre a farmácia e o medicamento em Portugal, da lavra de João Rui Pita e Ana Leonor Pereira em que é feito um resgate históricolegislativo para delinear a construção jurídico formal dos temas.

3 “Biomedizin als Rechtsgebiet", Medizinrecht 26 (2008) p. 57-61 
De autoria de Bruno Trancas e Fernando Vieira, tem-se ainda uma abordagem sobre a psiquiatria forense em Portugal, em um texto que abrange os aspectos médico-legais e psiquiátricos.

A coletânea ainda traz texto sobre a medicina familiar em que sua autora Maria Teresa Correia C.P.Tomé faz um contexto histórico, sanitária e legislativo desde o Século XVIII a 1945 sobre a temática da medicina doméstica, considerando que o Centro de Saúde é a peça basilar do sistema prestador dos cuidados de saúde primários em nível local, considerando muito importante a boa articulação entre os cuidados primários em saúde e os cuidados hospitalares.

Por fim, relata os direitos e deveres do médico e disserta sobre ser médico de família.

Marília Dourado, complementa a coletânea dissertando sobre o envelhecimento em diferentes perspectivas.

A entidade reguladora da saúde criada em 2003 em Portugal é o tema do capítulo de autoria de Jorge Simões e Luiz Vale Lima desvelando o sistema de saúde português em detalhes. 